\title{
The Sensitization of Aliphatic Epoxy Photopolymerization in Epoxy-Acrylate Interpenetrating Polymer Networks
}

\author{
Tetiana Samoilenko, Nataliia Iarova, Halyna Menzheres, Oleksandr Brovko \\ Institute of Macromolecular Chemistry of the National Academy of Ukraine, \\ Kharkivs'ke shose, 48, Kyiiv 02160, Ukraine
}

s.tf@ukr.net

Keywords: cationic photopolymerization, free-radical-promoted cationic polymerization process, photosensitization, aliphatic epoxy resin, epoxy-acrylate interpenetrating polymer networks.

The paper discuses the phenomenon of the sensitization of the aliphatic epoxy photopolymerization in the presence of acrylate oligomers while forming epoxy-acrylate interpenetrating polymer networks. The photopolymerization process was studied by IR spectroscopy and the properties of the final products - by the Gardner test, crosshatch adhesion test, and the pencil hardness test. The epoxy groups conversion, which is rather low in aliphatic epoxy polymers, was found to alter with the increase of acrylate compounds content. The materials synthesized on the base of interpenetrating polymer networks were shown to reveal fine properties and may have a potential application as coatings.

\section{Introduction}

Photopolymerization, which is known to be an easy, energy efficient, and solvent-free process, has become the successful technique of producing novel macromolecular materials. Photopolymerization via cationic mechanism, especially cationic ring-opening polymerization of epoxides, provides also such benefits as good polymer properties, low volume shrinkage, and an ability to proceed in the presence of air [1].

The main drawback of the use of epoxy monomers is related to their rather low photopolymerization speed [1, 2]. Different types of photosensitizators, facilitating the photoinitiator photolysis via redox reaction, have been already proposed to accelerate the epoxy polymerization $[1,2]$. Another approach is called free-radical-promoted cationic polymerization process (FRPCP) indicating that free radicals speed up ring-opening polymerization by producing more initiating and propagating cationic species $[2,3]$.

So, the objective of our work is to investigate the ability of free-radical polymerizable acrylate to promote the aliphatic epoxy polymerization during the formation of epoxy-acrylate interpenetrating polymer network (IPN), where acrylate will be not only a photosensitizer but also an active component of the system.

\section{Results and discussion}

At first the photopolymerization of neat aliphatic diepoxide 1-(2',3'-epoxypropoxymethyl)-1-(2",3"-epoxy-propoxy- 
methyl)-cyclohex-3-ene (UP-650 D) was studied by means of IR spectroscopy. The epoxy group conversion was followed by monitoring the absorbance decrease in the 908$914 \mathrm{~cm}^{-1}$ region attributed to the epoxy groups bending vibrations. Both epoxy groups have equal chemical structure and a single absorption band. To calculate the degree of conversion the internal reference band of asymmetric stretching vibrations of $-\mathrm{CH}_{2}$ group at the $2912-2914 \mathrm{~cm}^{-1}$ was chosen.

The calculations gave rather unsatisfactory data only $24.53 \%$ of epoxy groups conversion after $40 \mathrm{~min}$ of $\mathrm{UV}$ irradiation and $27.65 \%$ after further thermal post-treatment. Similar results have been also obtained by other scientists [4, 5], which confirms the pure reactivity of aliphatic epoxy resins in the photopolymerization process. Namely, the glycidyl epoxy groups are characterized by a long induction period and, due to their high mobility, by an ability to form a stable pseudo-five-membered ring with the neighboring oxygen atom of the ether group via hydrogen bonds. This results in the raise of the ring-opening reaction activation energy [6].

Therefore, it is important to enhance the rate of epoxy resins cationic photopolymerization. One of the ways of its accelerating is FRPCP - a novel process, which has been particularly illustrated by adding the small amounts of tris-(trimethylsilyl)silane generating active silyl radicals [3, 7]. Within this method it is also possible to use a photosensitizer both as the source of free radicals and as one of the basic components, capable to reveal other useful properties. Such approach was successfully used by applying a significant amount (almost 30\%) of Nvinylcarbazole also polymerizing in a system and improving the optical characteristics of epoxy polymers [2].

Considering this, it was decided to verify whether a diacrylate oligomer triethyleneglycol dimethacrylate (TEGDM) polymerizing via free radical mechanism will enhance a cationic photopolymerization of the aliphatic diepoxide. Moreover, the polymerization of the mixture of UP-650 D and TEGDM leads to the formation of simultaneous epoxy-acrylate IPNs - an interesting class of polymer materials that combines the best properties of their components $[1,8]$.

As we investigated earlier, in similar systems a cationic photoinitiator triphenylsulfonium hexafluoro-phosphate (TSHFP) can be used to induce both cationic and free radical polymerization processes [9, 10]. It is possible due to the fact that during its photocatalytic cleavage TSHFP produces not only cationic reactive species but also free radical ones (as depicted on the scheme below) and initiates two types of photopolymerizations [9-13]:

$$
\begin{aligned}
& \mathrm{Ar}_{3} \mathrm{~S}^{+} \mathrm{PF}_{6}^{-} \stackrel{\mathrm{hv}}{\longrightarrow}\left[\mathrm{Ar}_{3} \mathrm{~S}^{+} \mathrm{PF}_{6}^{-}\right]^{*} \longrightarrow \mathrm{Ar}+ \\
& +\mathrm{Ar}_{2} \mathrm{~S}^{+}+\mathrm{PF}_{6}^{-} \stackrel{\mathrm{RH}}{\longrightarrow} \mathrm{Ar}_{2} \mathrm{~S}+\mathrm{R}^{\bullet}+\mathrm{H}^{+} \mathrm{PF}_{6}^{-}+\mathrm{Ar}^{\bullet}
\end{aligned}
$$

The photopolymerization kinetics analysis of the UP-650 D with $25 \mathrm{wt} . \%$ of 
TEGDM mixture has shown a facilitating effect of the acrylate component: $40.48 \%$ of epoxy groups conversion after $40 \mathrm{~min}$ of UVirradiation and $47.58 \%$ after further thermal post-treatment respectively. The acrylate double bond conversion was also followed by monitoring the decrease of the absorbance band at $1637 \mathrm{~cm}^{-1}$. Their conversion levels up $98.06 \%$ after $20 \mathrm{~min}$ of UV-treatment.

The addition of more acrylate oligomer (50wt.\%) was found to cause the further enhancement of the ring-opening reaction. Thus, in a 50:50 epoxy-acrylate mixture the conversion of epoxy groups grows up to $91.14 \%$ after 40 min of irradiation (fig. 1). The double bond conversion reaches $92.06 \%$.

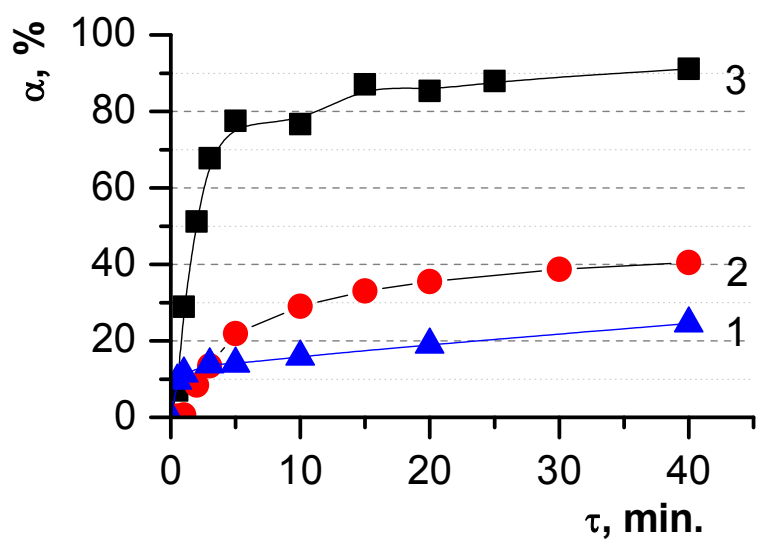

Figure 1. The kinetic curves of the epoxy groups conversion in UP-650 D: TEGDM: 1 - 100:0; 2 - 75:25; 3 - 50:50.

So, as it can be seen from a figure 1 , the conversion of epoxy groups increases with the raise of the acrylate content. Such effect is accounted for by the sensitizing influence of the free radicals on the cationic polymerization process [14]. The photoinitiated free-radical chain reaction induces the additional decomposition of a photoinitiator, which own quantum yield is rather low at the wavelength of $365 \mathrm{~nm}$, thereby generating a large number of cationic species capable of initiating epoxide ring-opening polymerization [2].

For the materials synthesized on the base of these epoxy-acrylate IPNs some physical properties were determined. Thus, the results of the pencil hardness test method has shown that the addition of the acrylate component improves the surface hardness of the films changing from HB for UP-650 D to F for UP-650 D:TEGDM in a 75:25 weight ratio and to $H$ for UP650 D:TEGDM in a 50:50 ratio.

The impact resistance of the coatings, which was determined for steel plates by the Gardner test method, was found to be very fine and the coatings withstand a strike of a weight falling from a maximum height of the used tester $(>50 \mathrm{~cm})$.

The crosshatch adhesion test method has shown that almost all samples reveal an excellent adhesion (100\%) to different substrates such as steel, aluminum, glass, and silicone.

\section{Conclusions}

Consequently, studying the photopolymerization kinetics by means of IR spectroscopy has shown that a rather inactive aliphatic diepoxide alone polymerizes much worse than in a mixture with an acrylate, forming a simultaneous epoxy-acrylate IPN. Such sensitizing effect of the free radical polymerization increases as the acrylate content growths and is accounted for the formation of 
more active centers inducing cationic polymerization.

The synthesized coatings are characterized by the excellent impact resistance and adhesion to different substrates as steel, glass, aluminum, and silicone. The surface hardness of free films was found to improve with the acrylate component addition.

So, the synthesis of the epoxy-acrylate IPNs not only facilitates the epoxy component photopolymerization via FRPCP but also allows creating new polymer materials with enhanced physical properties.

\section{Experimental part}

An aliphatic diepoxide 1-(2',3'-epoxypropoxymethyl)-1-(2",3"-epoxy-propoxymethyl)-cyclohex-3-ene (UP-650 D) was used as an epoxy component, difunctional triethyleneglycol dimethacrylate (TEGDM) as an acrylate component, and triphenylsulfonium hexafluorophosphate (TSHFP) (50 wt. \% solution in propylene carbonate). The chemical formulas of the used compounds are presented as mentioned:

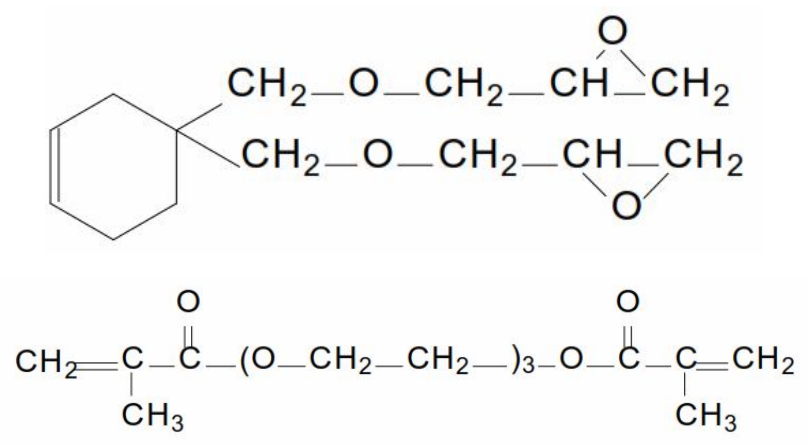



Epoxy and acrylate components were mixed in a 100:0, 75:25 or 50:50 weight ratio, 4.0 wt. $\%$ of the initiator solution was added to the mixture. The prepared formulation was sandwiched between two $\mathrm{NaCl}$ plates for IR method analysis and between two glass plates (previously coated with a solution of dimethyldichlorosilane in toluene in a 2:3 ratio as an anti-adhesive) to form free films for the pencil hardness test method. The formulation was also coated on defatted with $n$-hexane and then with propan-2-one (acetone) steel plates for the Gardner test method and on defatted steel, glass, and silicone plates, and aluminum foil for the crosshatch adhesion test method. Then the coated on different substrates liquid formulations were irradiated with the high pressure mercury-quartz UV lamp with the radiation maximum at the wavelength of $365 \mathrm{~nm}$. The light intensity at the sample position at $365 \mathrm{~nm}$ was $4 \mathrm{~mW} \mathrm{~cm}^{-2}$, as measured with the ATT-1515 radiometer. After that the samples were post-cured in an oven at $80^{\circ} \mathrm{C}$.

The photopolymerization kinetics was studied by means of IR spectroscopy (Tenzor 37 Brucker spectrophotometer). The IR spectra of the UV-cured samples were recorded at some time intervals in the range 4000 to $600 \mathrm{~cm}^{-1}$. 
The surface hardness of the cured films was measured by the pencil test method according to the ASTMD-3363-74. This method implies that the film surface hardness is equal to the hardness of the last pencil in a set (ranging here from soft to hard) which slate leaves no scratches on its surface:

$$
\text { 8B-7B-6B-5B-4B-3B-2B-B-HB-F-H- }
$$

\section{$2 \mathrm{H}-3 \mathrm{H}-4 \mathrm{H}-5 \mathrm{H}-6 \mathrm{H}-7 \mathrm{H}-8 \mathrm{H}-9 \mathrm{H}-10 \mathrm{H}$.}

The face impact resistance of the coatings was determined by a method of a striker impacted by a falling weight (Gardner test method) based on standard test method GOST 47-65-73. By means of an impact tester U-2 with a 1000 gram dart a maximum height of a dart position, which falls on the surface without rupturing, was measured.

Crosshatch adhesion to different substrates (steel, glass, silicone plates, and aluminum foil) was investigated according to the GOST 15240-78, by which a set of six parallel and six perpendicular cuttings are made at the distance of $3 \mathrm{~mm}$. The percent of film remaining on the substrate indicates the adhesion quality.

\section{References}

[1] C. Decker, T. N. T. Viet, D. Decker et al, Polymer. 2001, 42, 13, 5531-5541.

[2] Y. Hua, J. V. Crivello, J. Polym. Sci.: Part A: Polym. Chem., 2000, 38, 19, 3697-3709.

[3] M.-A. Tehfe, J. Lalevée, D. Gigmes et al, Macromolecules, 2010, 43, 3, 1364-1370.

[4] G. I. Menzheres,A. G. Diadiusha, V. N. Vatuliov et al, Jurn. prikl. himii, 1989, 62, 10, 2348-2352.
[5] M. S. Kligshtein,G. I. Menzheres,

A. A. Diegtiariova et al, Vysokomolekuliar. soiedinieniia, 1991, 33, 5, 973-978.

[6] U Bulut., J. V. Crivello, Macromolecules, 2005, 38, 9, 3584-3595.

[7] J. Lalevée, J. P. Fouassier, Polym. Chem., 2011, 43, 3, 1364-1370.

[8] T. F. Samoilenko, O. O Brovko, N. V Iarova, Polimernyi jurnal, 2014, 36, 1, 66-77.

[9] O. O Brovko., L. A. Honcharova, V. I. Shtompel et al, Polimernyi jurnal, 2005, 27, 1, 4550 .

[10] T. F. Samoilenko, O. O Brovko, N. V Iarova, G. I. Menzheres et al, XIII Ukraiins'ka konferentsiia z VMS, m. Kyiiv, 2013,. 290-292.

[11] Y. Cai, J. L. P. Jessop, Polymer, 2006, 47, 19, 6560-6566.

[12] J. V. Crivello, J. H. W. Lam J. Polym. Sci.: Polymer Lett. Ed., 1979, 17, 977, 759-764.

O. P. Batoh,

A. K. Chaiko, N. V. Vatuliov et al, Kompozyts. polimer. materialy, 1999, 21, 1, 41-45.

[14] L. Lecamp, C. Pavillon, P. Lebaudy, C. Bunel, Eur. Polym. J., 2005, 41, 1, 169-176. 